\title{
Multi-scale analysis of species-environment relationships
}

\author{
Simon F. Thrush ${ }^{1, *}$, Judi E. Hewitt ${ }^{1}$, Peter M. J. Herman ${ }^{2}$, Tom Ysebaert ${ }^{2}$ \\ ${ }^{1}$ National Institute of Water and Atmospheric Research, PO Box 11-115, Hamilton, New Zealand \\ ${ }^{2}$ Netherlands Institute of Ecology (NIOO-KNAW), Centre for Estuarine and Marine Ecology, Korringaweg 7, \\ 4401 NT Yerseke, The Netherlands
}

\begin{abstract}
Species-environment models are important tools for ecology and conservation, but ecologists generally lack knowledge of how spatial extent, habitat and environmental heterogeneity interact to affect relationships. This study investigates the effect of the spatial scale when predicting the response of maximum density and probability of occurrence of macrobenthic taxa to changes in sediment mud content. Three spatial scales were used, $2 \mathrm{~km}$ (an area within an estuary), $11 \mathrm{~km}$ (a single estuary) and $500 \mathrm{~km}$ (multiple estuaries), with the range of mud content being similar at the 2 largest spatial extents. Models from each scale were compared using model fit and the shape of the response curve. Different effects of scale were found for different model types and for different taxa, varying from no-scale dependence to markedly different responses at different scales. However, for most taxa, mud content was an important factor and qualitative responses could be predicted. Four species, the bivalves Austrovenus stutchburyi and Macomona liliana and the polychaetes Heteromastus filiformis and Nereidae, exhibited flat response curves, indicative of small changes in density over a broad range of mud content. Further analyses for these species indicated that general responses derived from a number of estuaries may reflect direct, local effects of mud content, but also 'mediated' effects, i.e. effects of other variables that correlate with mud content within an estuary, but have different correlations with mud content across estuaries. These results suggest that models should be validated against changes in environmental heterogeneity and spatial extent. Factors operating across scales may compound biases generated by unmeasured variables, but the use of models reflecting different aspects of spatial distribution (e.g. presence/absence, maximum density), incorporation of natural history information and the testing of hypotheses concerning the relationships developed at different scales may help determine the limits of extrapolation in the application and interpretation of species-environment models.
\end{abstract}

KEY WORDS: Regression models · Model assessment - Scale $\cdot$ Spatial extent · Ecological extent · Species-environment relationships

\section{INTRODUCTION}

Regression-based models are useful tools for identifying the relationships between biological and environmental variables. They can help forecast biological response to environmental change, refine our understanding of distribution patterns and help develop hypotheses and design experiments. In terrestrial ecosystems, species-environment relations are impor- tant conservation tools (Grand \& Cushman 2003). While the mechanistic processes that underpin these models do require investigation, it is also important that the statistical models are verified for general applicability at different space and time scales (Ysebaert \& Herman 2002).

Statistical models play an increasingly important role in risk assessment, as the threat of alterations in marine habitats due to changes in land-use, sea level, 
climate, and modifications to sediment disturbance regimes become more clearly recognised by resource managers, (Warwick et al. 1991, Ellis \& Schneider 1997, Ysebaert et al. 2002, Thrush et al. 2003). Statistical models represent emergent relationships determined by the grain (size of the sampling unit), lag (distance between samples) and extent (distance encompassed by the sampling programme) of the data modelled. Such models are particularly useful because they can often be developed even when the underlying mechanisms are complex and difficult to unravel.

There are a number of general environmental and biological factors that influence the distribution and abundance of soft-sediment macrofauna; for example, food supply, sediment grain size and hydrodynamic regime are commonly recognised as important (Gray 1974, Pearson \& Rosenberg 1987, Herman et al. 1999). Some factors directly influence an individual organism's neighbourhood (e.g. ability to maintain burrows and ventilate sediment). Other factors have both local and broader scale effects (e.g. sediment cohesiveness, stability, biogeochemistry and a predator's ability to search for prey), while still others are broad-scale factors operating over an estuary or regional scales (e.g. habitat connectivity and larval dispersal). Thus, general factors, such as sediment grain-size or hydrodynamics may directly, or mediated through other factors, have effects across a broad range of spatial scales. Moreover, how these various factors influence emergent pattern may differ from one location to another depending on the distribution of suitable habitats and the intensity of processes at particular locations (Levinton \& Kelaher 2004).

Given the broad range of scales over which processes operate, and the fact that processes interact, scaling issues reflect ecological phenomena that are important to model interpretations and are not solely statistical/sampling issues. Species-environment relations may change qualitatively and quantitatively with the scale of observation, if, at different scales, different processes drive emergent patterns. For example, a species may show optimal density within a particular estuary for depositional, relatively muddy areas. However, if this species is also limited by primary production, and if primary production is light-limited in turbid estuaries, then across estuaries the species may well show a preference for less muddy estuaries. Under this scenario, a species' overall response curve will encompass significant between-estuaries variation.

Scaling issues are thus important in validating statistical models, i.e. in translating statistically significant (regression) models into useful ecological knowledge and predictive tools. There are a variety of ways of validating regression models (Olden \& Jackson 2000); often paired samples are collected and 1 sample from each pair is used to build the model, or half the data is selected using a stratified random protocol to derive the model and the other half is used to test the model. Such tests assess how well the model predicts over the scale encompassed by sample pairs or the average distance between samples, while maintaining the same extent. These tests are useful, but do not assess general applicability (Olden \& Jackson 2000), nor do they necessarily fit with the way such models may be used to forecast distribution and abundance. It is most likely that species-environment models will be used to forecast distribution and abundance in a specific location. For example, if changes in land-use are predicted to change the distribution of muddy habitats in an estuary then the question to be answered is 'in this location, what are the expected long-term changes in the distribution and abundance of species relative to the predicted long-term habitat change?' Thus a potentially significant limitation is that the relationships observed may be scale dependent (Karl et al. 2000, Cushman \& McGarigal 2002). While data collected over a broad spatial extent may be the most appropriate for developing models, because it is likely to encompass a wide range of environmental conditions and density fluctuation, it may overlook finer- or broader-scale relationships. Rather than asking how well the models perform against scales of heterogeneity encompassed by data used to build the model, it may be more useful to assess models with independent data collected at different scales to that from which the model was derived.

In this paper we apply a multi-scale approach to assessing species-environment models, rather than testing how well a model predicts over the same extent. Models were developed to forecast changes in both the maximum density and the probability of occurrence of individual macrobenthic species associated with changes in sediment mud content (i.e. particles $<63 \mu \mathrm{m}$ ), from 3 independent data sets derived from sampling over different spatial scales (extents of 2, 11 and $500 \mathrm{~km}$ ). Models derived for each taxon from each of the 3 spatial scales were compared to indicate how effective these models were at explaining species-environment relationships and identify if fundamental changes in apparent preferences for fine or coarse sediment habitats occurred. Differences in models (either in effectiveness of the model to explain variation in the data or in the shape of the response curve) were used to provide useful ecological insights into the relationships between species and environmental gradients. Finally, for 4 species, the potential for mediating factors that vary between estuaries (e.g. productivity, recruitment) to generate estuary-specific responses was investigated.

As well as investigating similarity in the shape of the curve produced by models derived from data collected 
over different spatial extents and using this insight to help design sampling programmes to develop species-environment models, the analysis of scaledependent relationships can also help to discriminate whether environmental factors operate directly or are mediated by other factors. We propose 3 hypotheses concerning spatial-scale dependence of animal-sediment relations, based on differences in the form of curves produced by statistical models derived from data collected over different spatial scales. (1) If relationships derived from different scale data predict similar abundances (Fig. 1a), then sediment mud content has its strongest influence on local processes (e.g. ability to burrow through sediment). Species are directly limited by the local mud content, and sampling a mud gradient at any location within an estuary is sufficient to determine the species' general reaction to mud content. (2) If, however, at a broader scale, other factors (e.g. hydrodynamics, food availability, larval settlement, predator activity) are also important and overlay any response to mud then, although curves derived from different scales will have a similar shape, they will be offset on the $y$-axis and predict different abundances/occurrences (Fig. 1b). In this case sampling at the broad scale will provide the most generally applicable model. (3) However, if other factors important to species abundance vary differentially with mud content in different estuaries, then either different curves will be produced from different scales or flat response curves predicting small changes in abundance relative to variation in mud content will be apparent for a multi-estuary model (Fig. 1c). While the predictions based on data derived from several estuaries may not be valid for a specific estuary, important ecological insights into mediating processes can be gained. A fourth hypothesis, that sediment mud content did not influence the distribution and abundance of modelled taxa, was not considered as broad-scale relationships had already been established (Thrush et al. 2003).

\section{MATERIALS AND METHODS}

Scales. The independently collected data sets were derived from: (1) data from the control plots of a multisite experiment conducted in the Whitford embayment (Lohrer et al. 2004) and a nearby mud-to-sand transect as described in Thrush et al. (2003) (henceforth called $2 \mathrm{~km}$ extent scale), (2) authors' unpubl. data from a $11 \mathrm{~km}$ extent survey of intertidal benthic communities of the Whitford embayment (henceforth called $11 \mathrm{~km}$ extent scale) and (3) from the $500 \mathrm{~km}$ extent scale models, developed from sampling mud-to-sand transects in 19 estuaries and harbours (Thrush et al. 2003). The extent of each data set, in terms of distance encompassed by the samples, and the range of environmental conditions (sediment percent mud and tidal elevation) encompassed demonstrate that spatial extent was not directly related to the extent of these environmental variables (Table 1).

Data collection. The same corers were used in each study: for macrofauna (13 cm diameter, $15 \mathrm{~cm}$ depth); and for surface sediment chlorophyll $a$, sediment particle size, and organic matter ( $2 \mathrm{~cm}$ diameter, $2 \mathrm{~cm}$ depth).

The $2 \mathrm{~km}$ extent-scale data reflected a range of particle size, tidal elevation and sediment chlorophyll a content (Table 1). Samples were collected in summer (January 2002); 2 replicate macrofaunal and 2 surface sediment cores were taken from the experimental control plots in 4 locations, while along the transect, similar sampling was conducted at 12 locations, representing different sediment mud contents. The $11 \mathrm{~km}$ extent-scale data set was derived from 54 intertidal sites throughout the Whitford embayment. Samples were collected over $3 \mathrm{~d}$ in spring (October 2001). From each site 2 macrofaunal cores were taken (separated by $5 \mathrm{~m}$ ) along with 1 small core for analysis of sediment chlorophyll $a$, particle size, and organic matter. The $500 \mathrm{~km}$ extent-scale models described in Thrush et al. (2003) were based on sampling macrofauna and envi-

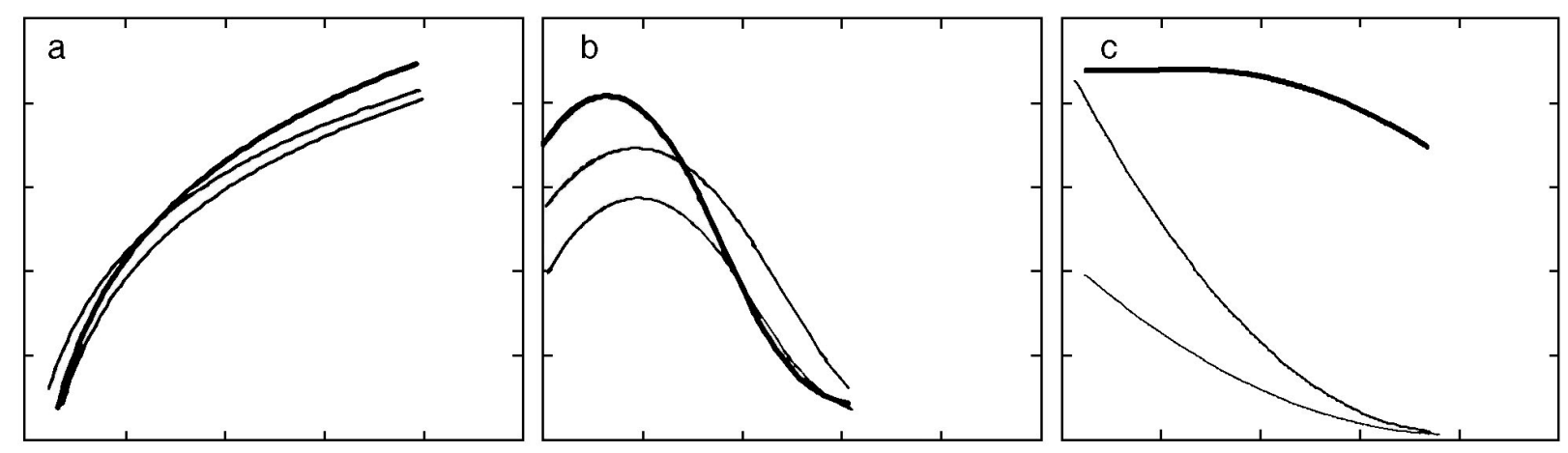

Fig. 1. (a) Consistent response curves at each scale (Hypothesis 1), (b) similar form of responses offset on the $y$-axis (Hypothesis 2) and (c) flat response curve at the multi-estuary scale (thick line) and different response curve shapes for different scales (Hypothesis 3) 
Table 1. Differences in spatial and environmental scale for the data used in the study. For tidal elevation MLW $=0$

\begin{tabular}{|c|c|c|c|}
\hline & $2 \mathrm{~km}$ extent & $11 \mathrm{~km}$ extent & $500 \mathrm{~km}$ extent \\
\hline Between-samples lag (m) & 2 & 5 & 1 \\
\hline Between station lag (m) & $20-400 \mathrm{~m}$ & $50-300 \mathrm{~m}$ & $10-100 \mathrm{~m}$ \\
\hline Estuary extent & 1 flat & 1 estuary & $\begin{array}{l}1 \text { flat, many } \\
\text { estuaries }\end{array}$ \\
\hline Variation in percent mud & $1-40$ & $0.5-95$ & $1-85$ \\
\hline Variation in tidal elevation (m) & ) $0.45-0.9$ & $-0.2-1.4$ & $0.45-1.1$ \\
\hline Sample size & 36 & 54 & 228 \\
\hline
\end{tabular}

ronmental variables along the mud-to-sand transition zone over 1 transect in 19 estuaries and harbours in the North Island of New Zealand. Sampling was conducted in spring to early summer (October to December 2000). In this survey, macrofauna were sampled using pairs of macrofaunal corers and smaller cores to sample sediment chlorophyll $a$, particle size, and organic matter at 12 locations on each transect.

For the 2 and $11 \mathrm{~km}$ extent-scale studies, macrofauna samples were sieved on a $0.5 \mathrm{~mm}$ mesh; for the $500 \mathrm{~km}$ extent-scale study macrofaunal samples were sieved on a $1 \mathrm{~mm}$ mesh. However, for most species, the 2 and $11 \mathrm{~km}$ extent-scale sampling was done prior to recruitment periods and small species and species with early recruitment were excluded from the comparisons, thus limiting any confounding of comparison across scale by differences in mesh size. In all studies, macrofauna samples were preserved in 70\% isopropyl alcohol (IPA) and stained with $0.2 \%$ Rose Bengal prior to identification and enumeration. All animals were identified to species level with the exception of Nereidae. While some Nereidae could be identified to species level (Nicon aestuariensis, and others to genera, Perinereis and Ceratonereis), taxonomic uncertainty in others led to us treating these as a single group. Counts of burrowing crabs (Helice crassa and Macrophthalmus hirtipes) were also amalgamated for analysis.

In each study, environmental parameters were analysed using the following techniques. To determine particle size, samples were digested in $6 \%$ hydrogen peroxide for $48 \mathrm{~h}$ to remove organic matter. Wet sieving was used to measure cumulative percent weights of gravel, coarse sand, medium sand, fine sand, and mud sediment fractions (i.e. particles sizes $>2,2-0.5$, $0.5-0.25,0.25-0.063,<0.063 \mathrm{~mm}$, respectively). Organic content was measured as loss on ignition in $5.5 \mathrm{~h}$ at $400^{\circ} \mathrm{C}$, after drying the samples at $60^{\circ} \mathrm{C}$ to a constant weight. Sediment samples for chlorophyll a analyses were kept chilled and in the dark while in the field, then freeze dried on return to the laboratory. Chlorophyll a was extracted from sediments by boiling in $95 \%$ ethanol, and the extract analysed using a spectrophotometer. An acidification step was used to separate degradation products from chlorophyll a (Sartory 1982).

Statistical methods. A variety of methods have been suggested for the analysis of relationships across multiple scales. For example, the indirect multi-scale method suggested by Wu et al. (2000) uses single scale methods that are repeated at different scales to identify positions of scale breaks and hierarchical structures (O'Neill et al. 1991, Wu \& Loucks 1995). Cushman \& McGarigal (2002) suggest a method for analysing hierarchical multi-scale species-environment relationships based on variance partitioning. This method is again for use where hierarchical structure is anticipated and requires a fully nested sampling design. We used a multi-level comparison of responses observed at different scales, thus enabling analysis of non-hierarchical scale relationships without a fully nested sampling design.

To compare species-environment relationships over the 3 spatial scales of sampling, we developed 2 types of regression model relating sediment mud fraction to the distribution and abundance of individual species. Firstly, the probability of occurrence was modelled using logistic regression on presence/absence data (Ysebaert et al. 2002). Secondly, the maximum density expected to occur was modelled following the methods proposed by Blackburn et al. (1992). A common phenomenon in ecology is for data points in scatter plots of species-environment data to be widely scattered beneath an upper (or above a lower) limit - a phenomenon described by Thomson et al. (1996) as a 'factor ceiling'. Maximum density models enable us to estimate the factor ceiling and determine the limits at which sediment mud content constrains species density. To develop these models, the sediment mud fraction, which varied over all samples from 0-95\% was divided into 11 equal classes (i.e. 0-9, 9.1-18\% etc), and the maximum density of an individual species found in each class calculated.

The functions used to model each species varied (e.g. linear, gaussian, polynomial) and were based on either raw or log transformed data. For the maximum density models, the number of samples occurring in each mud class were used as weightings. Relative changes in the Akaike's Information Criteria were used to select the best model for each taxon at each scale for both the logistic regression and maximum density models. For the 2 and $11 \mathrm{~km}$ extent scales, the small sample correction (Hurvich \& Tsai 1989) was used as the ratio of the number of samples to model parameters was less than 40 (Burnham \& Anderson 1998). Two types of comparisons were made across the 3 scales. Initially, the percentage of variance explained 
( $\mathrm{r}^{2}$ for the maximum density regressions) or the percent concordance with the model (for the logistic regressions) as the 3 scales were compared. However, as the quantity of data and its extent varied over different scales, the most informative comparison is the form (i.e. shape) that the modelled response curve takes for each spatial scale (i.e. changes in slope or locations of asymptotes for monotonic relationships or changes in height, breadth and location of peaks for more complex functions). These comparisons were made both visually and as suggested by van Belle (2002), i.e. determining whether overlap occurred between the 81st confidence interval about the regression parameters. These 2 methods were used rather than ANCOVA for the following reasons: (1) The number of non-linear responses; (2) differences in sample size between the different scales. For example, in the logistic models, a probability of occurrence of 0 or $100 \%$ is more likely with smaller sample size. For the maximum density models, maximums could be expected to increase with increased sampling, thus affecting slopes. Comparisons of location and breadth of asymptotes (for monotonic relationships) or peaks (for more complex functions) are more immune to this sample-size problem even for the maximum density models, as it is only the distribution of the sample sizes within the mud categories that is important, and, to a large extent, effects on this are accounted for by the weighted regression used to generate the response curve.

Finally, we investigated the potential for factors, varying among estuaries, to mediate responses to mud content over the 19 estuaries sampled at the $500 \mathrm{~km}$ extent scale, using a generalized linear model for Austrovenus stutchburyi, Macomona liliana, Heteromastus filiformis and Scoloplos cylindifer. This model assumed (over dispersed) Poisson errors, a log link, mud and mud $^{2}$ as continuous explanatory variables, estuary as a class variable, and an estuary $\times$ mud interaction term. It was fitted by restricted maximum likelihood. A posteriori, we compared estuary specific terms in the model (estuary and estuary $\times$ mud) with sediment organic content and chlorophyll concentrations measured along each transect and the characteristics of the estuaries identified in Thrush et al. (2003) (i.e. estuary type, area, tidal range, flushing time, catchment area, average mud content). No strong relationships were apparent $\left(\mathrm{r}^{2}<0.3\right)$ and this analysis is not discussed further.

\section{RESULTS}

\section{Variability between scales}

Prior to making comparisons between models, it is useful to consider the variability encompassed by the available data, as this is a major contributor to the models, especially the maximum density models based on the concept of factor ceilings. Data ranges exhibited by sediment organic matter, coarse particles and mud content were all highest at the 11 and $500 \mathrm{~km}$ extent scales (Fig. 2). Benthic chlorophyll $a$, however, had

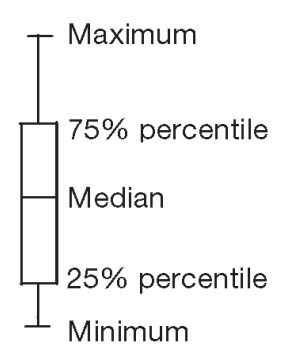

Fig. 2. Box plots showing data range of environmental variables measured at each scale
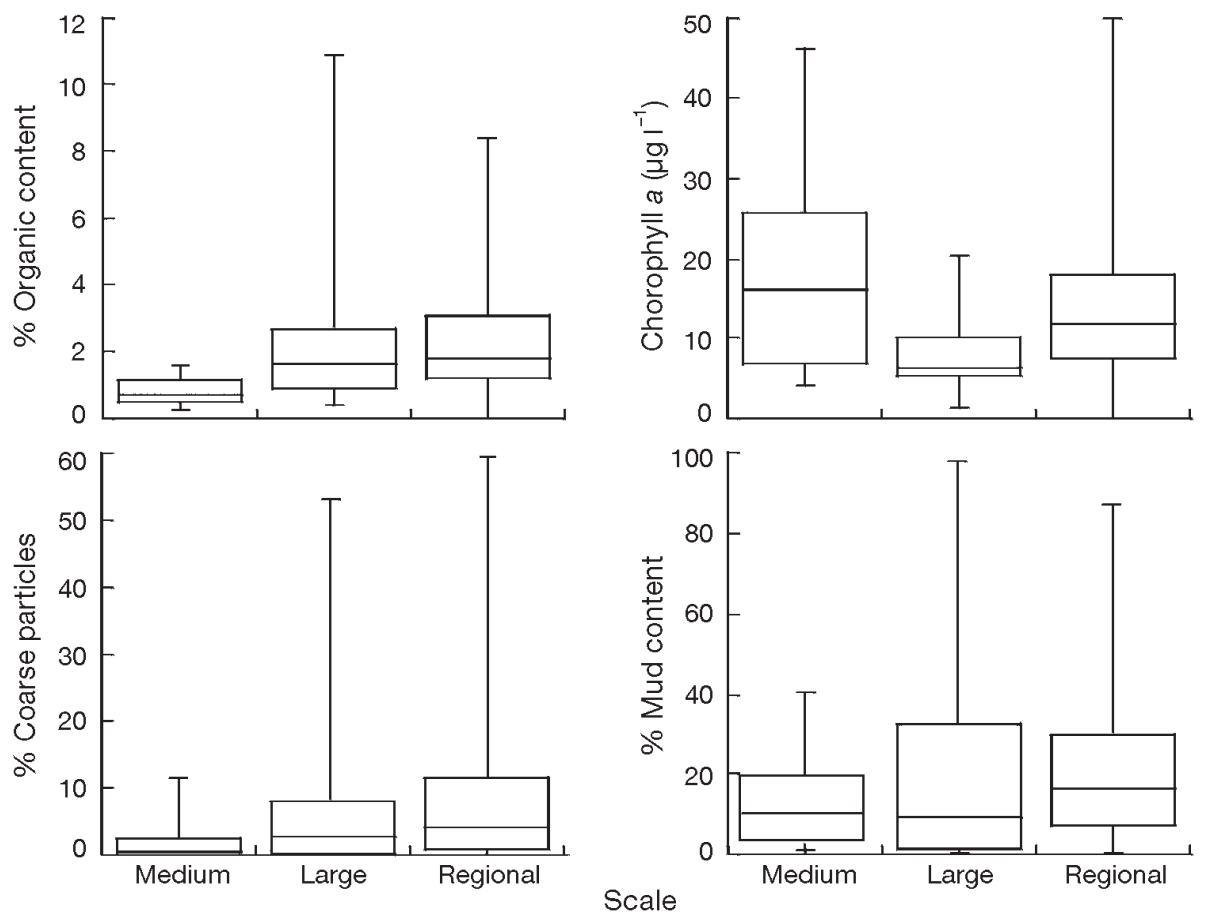
high ranges at both 2 and $500 \mathrm{~km}$ extent spatial scales. This difference may be partly attributed to sampling in different seasons, however, monitoring of chlorophyll $a$ on intertidal flats in the Auckland region shows more spatial than temporal variation (V. J. Cummings unpubl. data). None of the variables exhibited markedly higher variability at the $500 \mathrm{~km}$ extent scale.

Increasing the spatial extent of sampling did not always result in higher maximum and mean densities indicating no consistent relationship with scale for the 8 taxa modelled (Table 2). Only for Aonides oxycephala, Austrovenus stutchburyi and Heteromastus filiformis did estimates of the maximum density increase with increased sampling scale, while increases in mean density were only apparent for crabs and Heteromastus filiformis.

\section{Comparison of model fit across scales}

Significant logistic regression models were developed for most species for the 3 spatial scales (Table 3 ). Only the 2 polychaetes, Nereidae and Heteromastus filiformis, produced non-significant logistic regression models and in both cases these were at the smallest scale. For 5 of the 8 taxa, models with greater concordance were found at the smallest scale.
Significant maximum density models were also usually developed for the 3 spatial scales (Table 4). Crabs were the critical exception here; significant models could not be developed for the 500 and $2 \mathrm{~km}$ extent scales, also a significant model for nereids was not developed at the $11 \mathrm{~km}$ extent scale. The significant models account for a high proportion of the variability in maximum density, although there were no clear relationships between $\mathrm{r}^{2}$ and scale, except for Macomona liliana and Scoloplos cylindifer. Of the 8 taxa studied, the highest percentage of variance explained by the maximum density models was observed 4 times at the $2 \mathrm{~km}$ extent scale, 3 times at the $11 \mathrm{~km}$ extent scale and only once at the $500 \mathrm{~km}$ extent scale.

\section{Comparison of model form across scales}

Probability of occurrence models

Across the 3 spatial scales the functional form of the logistic regression models was frequently similar (Fig. 3), although for most taxa the probability of occurrence predicted at a particular sediment mud content varied between scales (Fig. 3). For the burrowing crabs, the relationships at all scales were

Table 2. Maximum, (mean) and minimum abundances (no. $265 \mathrm{~cm}^{-2}$ ) of each taxon found in the different studies

\begin{tabular}{|c|c|c|c|c|}
\hline \multirow{2}{*}{ Taxa } & \multirow{2}{*}{ Ecological characteristics } & \multicolumn{3}{|c|}{ — Scale } \\
\hline & & $2 \mathrm{~km}$ extent & $11 \mathrm{~km}$ extent & $500 \mathrm{~km}$ extent \\
\hline Anthopleura aureoradiata & Anthozoan, sedentary, predator & $32(1.7) 0$ & $25(8.4) 0$ & $44(10.8) 0$ \\
\hline Aonides oxycephala & $\begin{array}{l}\text { Spionid polychaete, burrower, } \\
\text { surface deposit feeder, } \\
\text { larval dispersal }\end{array}$ & $48(8.9) 0$ & $62(9.3) 0$ & $90(5.4) 0$ \\
\hline Austrovenus stutchburyi & $\begin{array}{l}\text { Venerid bivalve, mobile, } \\
\text { surface-dwelling, suspension } \\
\text { feeder, larval and post- } \\
\text { settlement dispersal }\end{array}$ & 56 (13.3) 0 & $76(11.1) 0$ & $85(10.8) 0$ \\
\hline $\begin{array}{l}\text { Crabs (Helice crassa, } \\
\text { Macrophthalmus hirtipes) }\end{array}$ & $\begin{array}{l}\text { Burrowing crabs, mobile, } \\
\text { surface deposit feeder/ } \\
\text { predator, brooders }\end{array}$ & $11(1.1) 0$ & $16(1.7) 0$ & $16(1.8) 0$ \\
\hline Heteromastus filiformis & $\begin{array}{l}\text { Capitellid polychaete, } \\
\text { burrower, sub-surface } \\
\text { deposit feeder }\end{array}$ & $37(0.85) 0$ & $20(2.9) 0$ & $83(10.4) 0$ \\
\hline Macomona liliana & $\begin{array}{l}\text { Tellinid bivalve, sediment- } \\
\text { dwelling, surface deposit } \\
\text { feeder, larval and post- } \\
\text { settlement dispersal }\end{array}$ & $22(8.4) 1$ & $18(4.6) 0$ & $25(5.1) 0$ \\
\hline Nereidae & $\begin{array}{l}\text { Polychaete, mobile burrower, } \\
\text { omnivore and deposit feeder, } \\
\text { brooder }\end{array}$ & $2(0.40) 0$ & $8(0.92) 0$ & $58(3.8) 0$ \\
\hline Scoloplos cylindifer & $\begin{array}{l}\text { Orbinid polychaete, burrower, } \\
\text { sub-surface deposit } \\
\text { feeder/grazer }\end{array}$ & $56(3.1) 0$ & $43(3.5) 0$ & $56(2.3) 0$ \\
\hline
\end{tabular}


Table 3. Logistic regression models for mud content at different scales. Values given in brackets after the model parameters are the 81st confidence intervals Model form: $p(x)=\frac{\mathrm{e}^{\text {exponent_coefficient }}}{1+\mathrm{e}^{\text {exponent_coefficient }}}$

\begin{tabular}{|c|c|c|c|c|}
\hline Таха & $\begin{array}{l}\text { Extent } \\
(\mathrm{km})\end{array}$ & $\begin{array}{c}\text { Concordance } \\
(\%)\end{array}$ & $\mathrm{p}$ & $\begin{array}{c}\text { Logistic model } \\
\text { exponent coefficients }\end{array}$ \\
\hline $\begin{array}{l}\text { Austrovenus } \\
\text { stutchburyi }\end{array}$ & $\begin{array}{c}500 \\
11 \\
2\end{array}$ & $\begin{array}{l}66.7 \\
66.4 \\
72.2\end{array}$ & $\begin{array}{l}0.0265 \\
0.0426 \\
0.0166\end{array}$ & $\begin{array}{c}4.55(1.1)-0.72(0.35) \ln (\mathrm{mud}) \\
0.64(0.35)-0.33(0.17) \ln (\mathrm{mud}) \\
2.2(0.86)-0.89(0.42) \ln (\mathrm{mud})\end{array}$ \\
\hline $\begin{array}{l}\text { Anthopleura } \\
\text { aureoradiata }\end{array}$ & $\begin{array}{c}500 \\
11 \\
2\end{array}$ & $\begin{array}{l}67.4 \\
74.4 \\
91.1\end{array}$ & $\begin{array}{r}0.0004 \\
<0.0001 \\
<0.0001\end{array}$ & $\begin{array}{c}0.90(0.42)-0.045(0.015) \mathrm{mud} \\
0.56(0.21)-0.11(0.060) \mathrm{mud} \\
3.88(1.3)-0.59(0.21) \mathrm{mud}\end{array}$ \\
\hline $\begin{array}{l}\text { Aonides } \\
\text { oxycephala }\end{array}$ & $\begin{array}{c}500 \\
11 \\
2\end{array}$ & $\begin{array}{l}73.4 \\
70.8 \\
82.6\end{array}$ & $\begin{array}{r}<0.0001 \\
0.0059 \\
<0.0001\end{array}$ & $\begin{array}{c}1.16(0.54)-0.05(0.013) \mathrm{mud} \\
-0.16(0.34)-0.048(0.027) \mathrm{mud} \\
1.58(0.82)-0.48(0.20) \mathrm{mud}\end{array}$ \\
\hline Crabs & $\begin{array}{c}500 \\
11 \\
2\end{array}$ & $\begin{array}{l}75.1 \\
87.4 \\
83.7\end{array}$ & $\begin{array}{r}<0.0001 \\
<0.0001 \\
0.0072\end{array}$ & $\begin{array}{c}-2.95(1.1)+1.07(0.19) \ln (\mathrm{mud}) \\
-2.56(0.65)+0.98(0.25) \ln (\mathrm{mud}) \\
-3.96(1.4)+1.33(0.59) \ln (\mathrm{mud})\end{array}$ \\
\hline $\begin{array}{l}\text { Scoloplos } \\
\text { cylindifer }\end{array}$ & $\begin{array}{l}500 \\
11\end{array}$ & 66.2 & $\begin{array}{l}0.0123 \\
0.0352\end{array}$ & $\begin{array}{c}-0.33(0.15)+0.06(0.049) \mathrm{mud} \\
-0.002(0.001) \mathrm{mud}^{2} \\
-0.53(0.37)+0.09(0.05) \mathrm{mud} \\
-0.0015(0.001) \mathrm{mud}^{2} \\
-0.74(0.27)+0.28(0.20) \mathrm{mud} \\
-0.008(0.008) \mathrm{mud}^{2}\end{array}$ \\
\hline $\begin{array}{l}\text { Macomona } \\
\text { liliana }\end{array}$ & $\begin{array}{l}500 \\
11\end{array}$ & 64.1 & $\begin{array}{l}<0.0001 \\
<0.0001\end{array}$ & $\begin{array}{c}0.76+0.69(0.36) \ln (\mathrm{mud}) \\
-0.2(0.081) \ln (\mathrm{mud})^{2} \\
1.6(0.44)+0.43(0.47) \ln (\mathrm{mud}) \\
-0.39(0.17) \ln (\mathrm{mud})^{2} \\
58(26.2)-51(22.6) \ln (\mathrm{mud}) \\
+10(4.6) \ln (\mathrm{mud})^{2}\end{array}$ \\
\hline Nereidae & $\begin{array}{c}500 \\
11 \\
2\end{array}$ & $\begin{array}{l}65.7 \\
75.0 \\
61.0\end{array}$ & $\begin{array}{l}0.0098 \\
0.0067 \\
0.2236\end{array}$ & $\begin{array}{c}-0.44(0.34)+0.6(0.25) \ln (\mathrm{mud}) \\
-1.61(0.46)+0.47(0.18) \ln (\mathrm{mud}) \\
-0.8(0.16)+0.37(0.32) \ln (\mathrm{mud})\end{array}$ \\
\hline $\begin{array}{l}\text { Heteromastus } \\
\text { filiformis }\end{array}$ & $\begin{array}{c}500 \\
11\end{array}$ & $\begin{array}{l}64.5 \\
59.0\end{array}$ & $\begin{array}{l}0.0135 \\
0.0638\end{array}$ & $\begin{array}{c}0.36(0.12)+0.45(0.18) \ln (\mathrm{mud}) \\
-0.93(0.438)+0.077(0.042) \mathrm{mud} \\
-0.00083(0.00047) \mathrm{mud}^{2} \\
-1.24(0.66)+0.27(0.34) \ln (\mathrm{mud})\end{array}$ \\
\hline
\end{tabular}

the data range, indicating that from the sample sites used in the $500 \mathrm{~km}$ extent models these bivalves are ubiquitous irrespective of sediment particle size.

For Heteromastus filiformis, the best fit at the $11 \mathrm{~km}$ extent scale differed to those derived for the other scales (Table 3, Fig. 3). Significant differences were also observed between the regression models at the different scales for Anthopleura aureoradiata, Aonides oxycephala, Macomona liliana, and Scoloplos cylindifer, as indicated by the non-overlapping confidence intervals for the model coefficients (Table 3).

\section{Maximum density models}

As expected, the $500 \mathrm{~km}$ extent scale models consistently predicted higher maximum densities than the smaller scale models (Fig. 4). The sediment mud content predicted to result in the highest density was similar at all scales for 6 of the 8 taxa, although similar to the probability of occurrence models, prediction of lowest density relative to mud content showed more variation between scales.

Consistency in models from the different scales were observed for Aonides oxycephala and Scoloplos cylindifer only, although there was general

consistent (i.e. not significantly different from each other). Most of the taxa showed monotonic relationships with the probability of occurrence either increasing or decreasing with sediment mud content at all scales, implying that models produced over any of the spatial scales provide a gross qualitative indication of particle size preference. For species with monotonic relationships, generally the curves of the $500 \mathrm{~km}$ extent scale models had a higher probability of occurrence over a wider range. Scoloplos cylindifer and Macomona liliana exhibited polynomial functions; the height of which varied markedly with scale although there was no clear sequence of change associated with scale. Austrovenus stutchburyi, Heteromastus filiformis and Macomona liliana showed an interesting discrepancy between the $500 \mathrm{~km}$ extent and smaller scale models. For all 3 species, the $500 \mathrm{~km}$ extent model predicted a small range of probabilities in occurrence less than $50 \%$ of similarity in the functional form of models across scales for Austrovenus stutchburyi, Anthopleura aureoradiata and crabs. Different model forms were apparent at the $500 \mathrm{~km}$ extent scale for Heteromastus filiformis, Macomona liliana and Nereidae. M. liliana changed from a convex polynomial function at the $500 \mathrm{~km}$ extent scale to forms reflecting sharp monotonic decreases at the 11 and $2 \mathrm{~km}$ extent scales, whereas $H$ filiformis, and Nereidae showed distinct peaks in maximum density at the $500 \mathrm{~km}$ extent scale but much weaker responses to changes in sediment mud content at the 2 smaller scales. Fig. 5 illustrates how the function at the $500 \mathrm{~km}$ extent scale could be influenced by the density pattern observed in 1 estuary, where $M$. liliana was observed in relatively high abundances over a wide range of mud content and $H$. filiformis exhibited exceptionally high and increasing density up to about $40 \%$ mud content in 1 estuary. 
Table 4. Maximum density regression models for mud content at different scales. Values given in brackets ( ) after the model parameters are the 81st confidence intervals. Model form: $Y=$ values

\begin{tabular}{|c|c|c|c|c|}
\hline Taxa & $\begin{array}{c}\text { Extent } \\
(\mathrm{km})\end{array}$ & $r^{2}$ & $\begin{array}{c}\mathrm{P} \\
\text { (model) }\end{array}$ & Maximum density model values \\
\hline Austrovenus stutchburyi & $\begin{array}{c}500 \\
11 \\
2\end{array}$ & $\begin{array}{l}0.86 \\
0.94 \\
0.92\end{array}$ & $\begin{array}{r}0.0003 \\
<0.0001 \\
0.0433\end{array}$ & $\begin{array}{l}118.6(6.6)-25.2(3.9) \ln (\mathrm{mud}) \\
119.2(6.2)-29.6(2.5) \ln (\mathrm{mud}) \\
89.2(15.4)-36.2(7.8) \ln (\mathrm{mud})\end{array}$ \\
\hline Anthopleura aureoradiata & $\begin{array}{c}500 \\
11 \\
2\end{array}$ & $\begin{array}{l}0.95 \\
0.93 \\
0.92\end{array}$ & $\begin{array}{r}<0.0001 \\
<0.0001 \\
0.0448\end{array}$ & $\begin{array}{l}48.5(3.2)-11.8(1.0) \ln (\mathrm{mud}) \\
66.3(4.1)-16.8(1.7) \ln (\mathrm{mud}) \\
59.5(8.7)-20.1(4.4) \ln (\mathrm{mud})\end{array}$ \\
\hline Aonides oxycephala & $\begin{array}{c}500 \\
11 \\
2\end{array}$ & $\begin{array}{l}0.75 \\
0.94 \\
0.85\end{array}$ & $\begin{array}{r}0.0011 \\
<0.0001 \\
0.0800\end{array}$ & $\begin{array}{l}147.2(22.1)-31.7(6.4) \ln (\mathrm{mud}) \\
110.0(16.3)-27.7(2.5) \ln (\mathrm{mud}) \\
110(17.4)-29.2(8.8) \ln (\mathrm{mud})\end{array}$ \\
\hline Crabs & $\begin{array}{c}500 \\
11 \\
2\end{array}$ & $\begin{array}{l}0.20 \\
0.72 \\
0.32\end{array}$ & $\begin{array}{l}0.2315 \\
0.0020 \\
0.4376\end{array}$ & $\begin{array}{l}9.14(2.2)+0.042(0.032) \mathrm{mud} \\
0.52(1.1)+0.57(0.035) \mathrm{mud} \\
1.65(2.4)+0.20(0.021) \mathrm{mud}\end{array}$ \\
\hline Scoloplos cylindifer & $\begin{array}{c}500 \\
11 \\
2\end{array}$ & $\begin{array}{l}0.93 \\
0.94 \\
0.98\end{array}$ & $\begin{array}{r}<0.0001 \\
<0.0001 \\
0.0091\end{array}$ & $\begin{array}{l}90.8(13.4)-21.9(2.1) \ln (\mathrm{mud}) \\
65.5(13.3)-18.5(1.4) \ln (\mathrm{mud}) \\
90.8(14.4)-23.2(2.2) \ln (\mathrm{mud})\end{array}$ \\
\hline Macomona liliana & $\begin{array}{c}500 \\
11 \\
2\end{array}$ & $\begin{array}{l}0.78 \\
0.95 \\
0.98\end{array}$ & $\begin{array}{r}0.0048 \\
<0.0001 \\
0.0870\end{array}$ & $\begin{array}{l}21.6(7.9)+0.146(0.17) \\
\mathrm{mud}-0.005(0.002) \mathrm{mud}^{2} \\
-1.68(1.1)+90(0.001) / \mathrm{mud} \\
-5.2(3.3)+121.6(16.7) / \mathrm{mud}\end{array}$ \\
\hline Nereidae & $\begin{array}{c}500 \\
11 \\
2\end{array}$ & $\begin{array}{l}0.63 \\
0.13 \\
0.98\end{array}$ & $\begin{array}{r}0.062 \\
0.4033 \\
<0.0001\end{array}$ & $\begin{array}{l}48.1(0.001) \mathrm{e}^{-0.5\{[\operatorname{mud}-36.5(0.05)] / 21.3(0.05)\} 2} \\
8.1(3.9) \mathrm{e}^{-0.5\{[\operatorname{mud}-3.58(1.7)] / 5.9(9.3)\} 2} \\
2.18(0.003) \mathrm{e}^{-0.5\{[\operatorname{mud}-9.0(0.025)] / 10.8(0.05)\} 2}\end{array}$ \\
\hline Heteromastus filiformis & $\begin{array}{c}500 \\
11 \\
2\end{array}$ & $\begin{array}{l}0.89 \\
0.54 \\
0.98\end{array}$ & $\begin{array}{r}0.0065 \\
0.0204 \\
<0.0001\end{array}$ & $\begin{array}{l}24.6(8.2)+59.5(2.9) \mathrm{e}^{-0.5\{[\operatorname{mud}-29.1(1.5)] / 14.7(0.67)] 2} \\
30.26(7.8)-22.3(6.3) \mathrm{e}^{-0.5\{[\operatorname{mud} / 36.2(17.2)] / 30.3(3.8)\} 2} \\
21.9(0.001) \mathrm{e}^{-0.5\{[\operatorname{mud}-7.87(0.0001)] / 7.94(0.0001) \mid 2}\end{array}$ \\
\hline
\end{tabular}

\section{Factors mediating responses to mud content}

The potential for estuary specific effects to drive the $500 \mathrm{~km}$ scale models was illustrated for Macomona liliana, Austrovenus stutchburyi, Heteromastus filiformis and Scoloplos cylindifer. A. stutchburyi, M. liliana and $H$. filiformis exhibited reasonably flat probability of occurrence curves at the $500 \mathrm{~km}$ extent scale (Fig. 3) reflecting high-predicted probability of occurrence across the range of sediment mud content. In contrast, S. cylindifer showed a preference for $<40 \%$ mud across scales. For the maximum density models (Fig. 4), H. filiformis and $M$. liliana showed different functional forms at the $500 \mathrm{~km}$ extent scale than at the 2 smaller scales, whereas A. stutchburyi and S. cylindifer exhibited similar functional forms across scales. Nereidae also showed a different functional form at the $500 \mathrm{~km}$ scale, however we did not include this taxa in the analysis of individual estuaries because of the potential to confound responses of different species in different estuaries.

The analysis of mean abundances by generalized linear models for the 4 species at the $500 \mathrm{~km}$ extent scale revealed some interesting contrasts that help to explain the variation in response observed across scales (Table 5). For each species the significant interaction term between estuary and mud indicated that different relationships with mud were apparent at least in some estuaries. Interestingly, of the 4 species analysed Scoloplos was the only one where mud was not a significant factor, which is in contrast to the results generated by the probability of occurrence and maximum density models.

These results can be explained by analysis of the individual estuary sediment response curves (Fig. 5). It is striking that the curves for both Macomona liliana and Austrovenus stutchburyi from different estuaries were often of similar form, but shifted to the right or left according to the range of observed mud concentrations. This suggests that relative rather than absolute changes of mud content within estuaries were important and resulted in flat response curves when data from a number of estuaries was used to generate species-environment responses. For Heteromastus filiformis and Scoloplos cylindifer, although many of the curves from individual estuaries were of similar form, there were also important differences between estuaries in the effect 

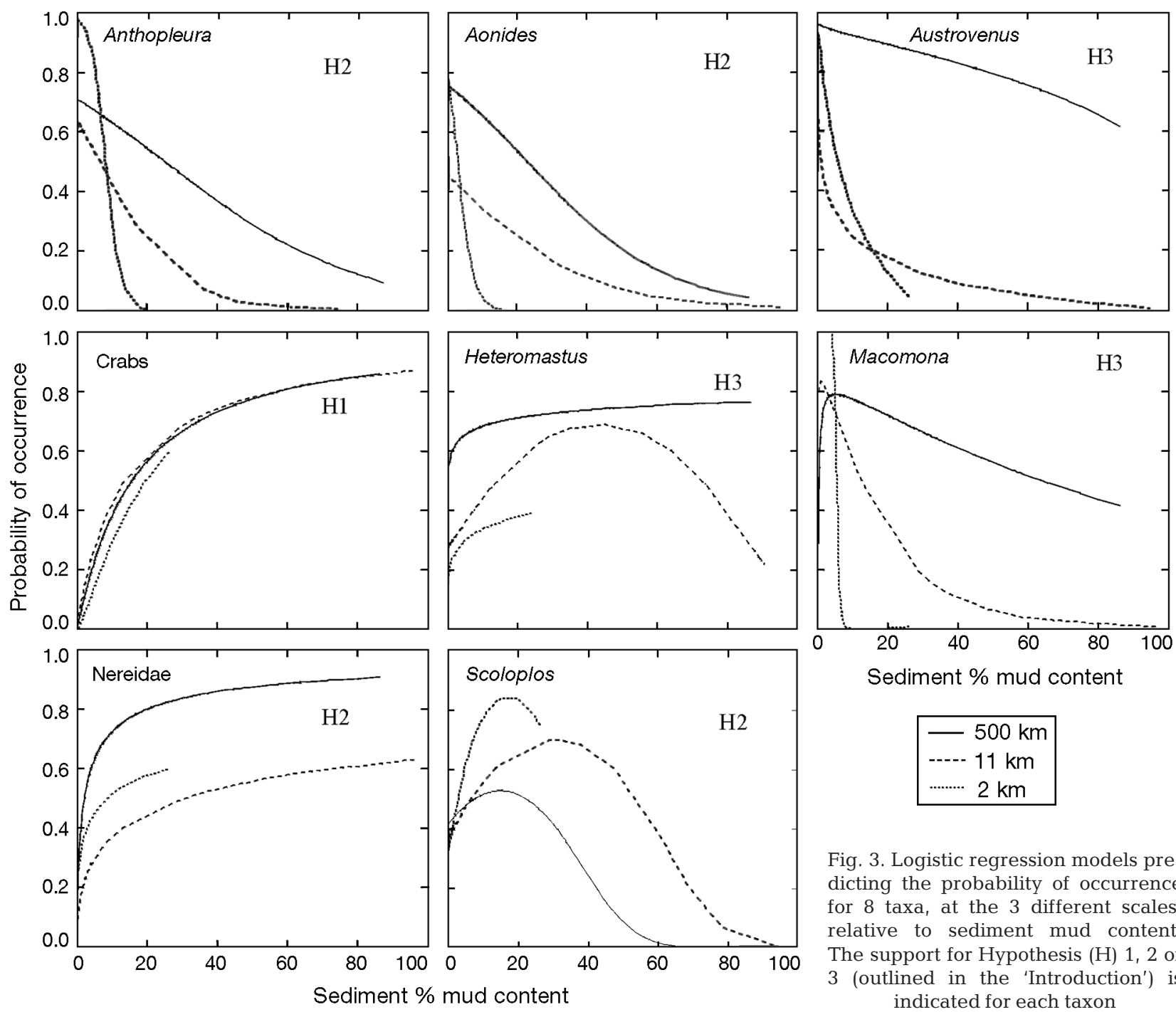

Sediment \% mud content

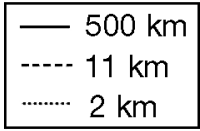

Fig. 3. Logistic regression models predicting the probability of occurrence for 8 taxa, at the 3 different scales, relative to sediment mud content. The support for Hypothesis (H) 1, 2 or 3 (outlined in the 'Introduction') is indicated for each taxon

of mud on abundance (Fig. 5). For both worms, this is indicated by the few curves that showed increasing density. For $H$. filiformis, the results probably reflect a patchy distribution of the worm between estuaries and generally low density. For $S$. cylindifer, 1 estuary exhibited numbers that were very low or 0 at low mud content, then increased and very suddenly dropped to 0 over a very narrow range of mud content. The model was not able to capture this sudden drop, and translated it into an increase with mud content. The 'high' density achieved at mud contents around $20 \%$ was not really higher than in other estuaries, rather the density for low mud content was in comparison too low. The individual estuary curves all indicated that $S$. cylindifer was not found at intermediate to high mud contents, but that other factors determine whether sandy sediments are suitable for the species or not.

\section{DISCUSSION}

Our results demonstrated a mixed response to the predictions made on the scale dependence of animalsediment relations, depending on whether occurrence or maximum density was modelled, with only 3 of the 8 taxa studied (Anthopleura aureoradiata, Heteromastus filiformis and Macomona liliana) showing similar changes over scale for both models (Figs. 3 \& 4). The majority of taxa /model types revealed patterns in animal-sediment relationships that supported Hypotheses 2 and 3, indicating that broad-scale relationships emerge from additive or interactive processes operating across scales rather than local responses to mud being the dominant factor limiting distribution (Hypothesis 1). The differing results for different taxa and model types suggest there is no simple panacea when studying species-environment relationships, in partic- 

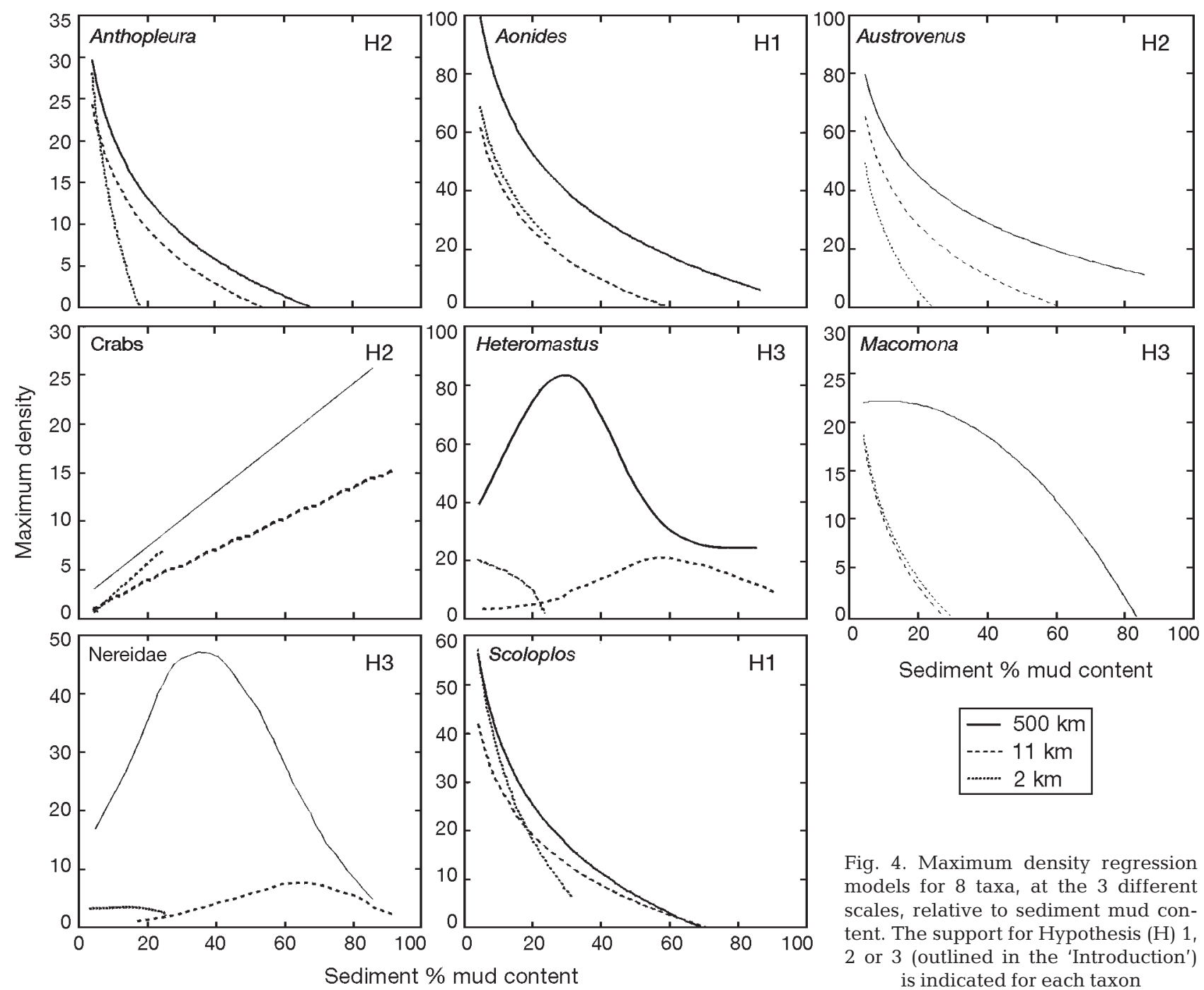

Fig. 4. Maximum density regression models for 8 taxa, at the 3 different scales, relative to sediment mud content. The support for Hypothesis $(\mathrm{H}) 1$, 2 or 3 (outlined in the 'Introduction') is indicated for each taxon

ular there is no single right scale of sampling to determine species-environment relationships. On one hand, increasing the extent of the data used to develop the model resulted in developing the model over a broader range of sediment mud content and including a wider density range, but on the other hand, such broad-scale sampling can include factors that mediate the direct relationship between mud content and density. Testing for the scale-dependence of relationships thus becomes essential.

While some taxa exhibited model curves that were consistent across scales, indicating that increasing the spatial extent of models is not always necessary, species responses were dependent on model type. For the maximum density models, consistent models across scales were developed for both Aonides oxycephala and Scoloplos cylindifer, polychaetes with restricted mobility, emphasising the importance of local sediment characteristics or another variable operating on the same scale for which mud content is a good surrogate (Hypothesis 1). Both worms are often patchily distributed, with occasional high-density patches; thus maximum density models may be more responsive than occurrence models. In contrast, for the probability of occurrence models, crabs exhibited the tightest fit to Hypothesis 1. While crabs need sediment of a particular muddiness and cohesiveness to establish and maintain burrows, they tend to be more evenly distributed within mudflats.

For both model types, approximately half the taxa matched Hypothesis 2, i.e. a similar form of response across scales (e.g. decreases, increases or unimodal), although the absolute abundance (or occurrence) predicted changed. This suggests that, as scale increases, other factors become important. Estuaries sampled at a $500 \mathrm{~km}$ extent scale are likely to encompass variations in temperature, oceanic influences, terrestrial influences, species pools and larval supply. Variations in 

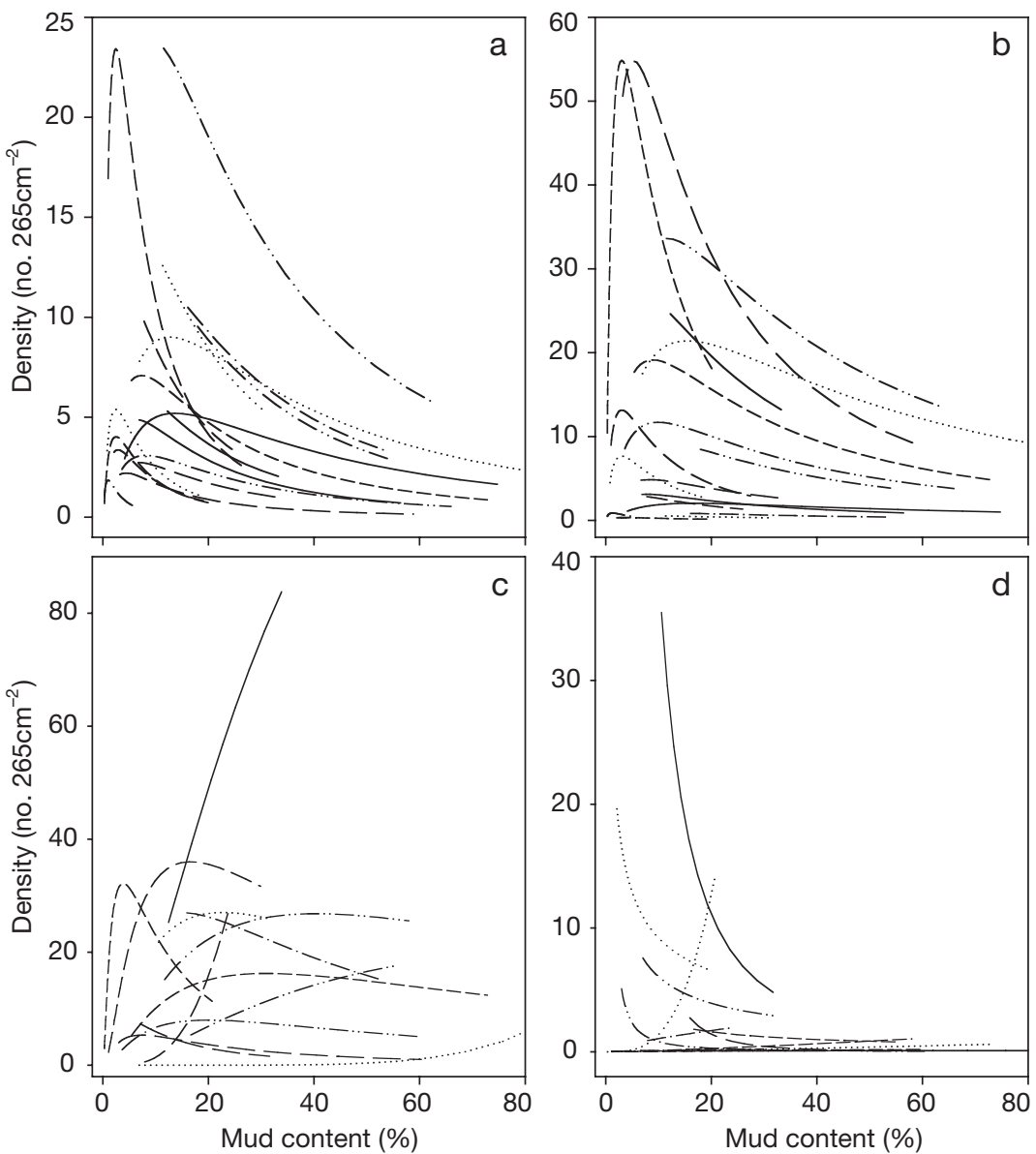

Fig. 5. Fitted functions of the relationship between (a) Macomona liliana (b) Austrovenus stutchburyi, (c) Heteromastus filiformis and (d) Scoloplos cylindifer density (number per $265 \mathrm{~cm}^{2}$ ) and sediment mud content for 18 estuaries. Curves were only drawn for the range of mud contents observed in each estuary

such factors, together with more localised environmental heterogeneity (e.g. wave exposure, elevation, sediment food quality) are likely to mediate ecological responses to variables such as sediment particle size (e.g. Cummings et al. 2001, Norkko et al. 2001). Anthopleura aureoradiata was the only species where both models of maximum density and probability of occurrence implied that other factors become important, over laying the effect of mud, with increasing scale. This small anemone requires an attachment site to maintain itself in sandy sediments and is often found attached to either live or dead Austrovenus stutchburyi shells. While there is some similarity in the form of models produced for A. stutchburyi and A. aureoradiata, differences between probability of occurrence models for the 2 species indicate that $A$. aureoradiata is not limited by substrate alone. For taxa that match hypothesis 2, sampling at the broad scale will provide the most generally applicable model. However, observing qualitatively similar responses across estuaries and scales means that we can predict that, for certain ranges of mud content, the density is expected to decline, increase or stay constant. This result has important practical implications for our ability to forecast the effect of anthropogenic stress on the distribution of species.

Our third hypothesis, indicative of interactions occurring between the effect of sediment mud content and other factors, was met for Austrovenus stutchburyi, Macomona liliana and Heteromastus filiformis under probability of occurrence models and M. liliana, Nereidae and $H$. filiformis under maximum density models. The 2 bivalves, $A$. stutchburyi and $M$. liliana, and the polychaete $H$. filiformis exhibited very flat responses to mud content at the multiestuary scale, particularly for probability of occurrence, and for these species we developed generalised linear models to assess the importance of interaction between the effects of sediment mud content and estuary. The polychaete Scoloplos cylindifer was also included for comparative purposes. The generalised linear modelling of these species' abundances at the $500 \mathrm{~km}$ extent revealed significant interactions between estuary and mud content, suggesting a potential role for factors that correlate with mud content (e.g. food availability, larval settlement, predator activity). There was no relationship between average estuary mud content and average density of these species, indicating that at betweenestuary scales other factors are important. A. stutchburyi and $M$. liliana appeared to be affected by relative change in mud content rather than absolute values. Juveniles of these 2 species undergo post settlement dispersal in the water column, however, they differ markedly in other aspects of their ecology; A. stutchburyi is a surface-dwelling suspension feeder and $M$. liliana is a sediment-dwelling surface-deposit feeder. For the relatively immobile $S$. cylindifer and $H$. filiformis, density variations between estuaries, low abundance and, for $S$. cylindifer, responses to environmental factors within sandy habitats appear to be important. For A. stutchburyi, M. lililana and H. filiformis, mud content appears to reflect both direct and indirect effects, consistent with the view that species respond to ecological processes operating simultaneously over a variety of scales, thus different factors may be limiting at different scales (Wiens 1989). 
Table 5. Significance tests based on the Wald statistic for all terms in the generalized linear models developed for Macomona liliana, Austrovenus stutchburyi, Heteromastus filiformis and Scoloplos cylindifer. A Poisson distribution with log link and over dispersion were assumed in the model fitting. The fitted model initially contained the following terms: Pred $=\mu+$ estuary + estuary $\times \ln ($ mud $)+\alpha \times \ln ($ mud $)+$ $\beta \times[\ln (\mathrm{mud})]^{2}$, but non-significant terms were subsequently dropped from the model. $\alpha, \beta$ : constants; $\mu$ : mean intercept; estuary: categorical variable

\begin{tabular}{|lcccc|}
\hline Species & Model term & df & Wald & $\mathrm{p}$ \\
\hline Macomona & Intercept & 1 & 104.3737 & 0.000000 \\
& $\ln (\mathrm{mud})$ & 1 & 58.2977 & 0.000000 \\
& $\ln (\mathrm{mud})^{2}$ & 1 & 18.5689 & 0.000016 \\
& Estuary & 17 & 170.4165 & 0.000000 \\
Eustrovenus & Estuary $\times \ln (\mathrm{mud})$ & 17 & 40.1620 & 0.001228 \\
& Intercept & 1 & 39.4640 & 0.000000 \\
& $\ln (\mathrm{mud})^{2}$ & 1 & 33.8643 & 0.000000 \\
Heteromastus & Estuary & 18 & 319.1399 & 0.000000 \\
& Estuary $\times \ln (\mathrm{mud})$ & 18 & 73.6472 & 0.000000 \\
& Intercept & 1 & 66.2006 & 0.000000 \\
Scoloplos & $\ln (\mathrm{mud})$ & 1 & 12.2968 & 0.000454 \\
& $\ln (\mathrm{mud})^{2}$ & 1 & 20.6654 & 0.000005 \\
& Estuary & 12 & 189.0004 & 0.000000 \\
& Estuary $\times \ln (\mathrm{mud})$ & 12 & 79.1255 & 0.000000 \\
& Intercept & 1 & 1.98874 & 0.158472 \\
& Estuary & 12 & 67.84248 & 0.000000 \\
& Estuary $\times \ln (\mathrm{mud})$ & 12 & 26.93486 & 0.007896 \\
\hline
\end{tabular}

Analysis across a wider range of species is needed to identify whether specific natural history or functional characteristics are helpful in predicting animalsediment responses across scales. Although we expect natural history information to be important in helping to interpret patterns, the variation in responses apparent from probability of occurrence, maximum density and generalised linear (mean abundance) models also highlights the importance of spatial variability of abundance in influencing apparent scale-dependence. This further emphasises the value of considering environmental variables as constraints on organisms rather than correlates and modelling changes at or near the maximum response (Blackburn et al. 1992, Cade et al. 2005). When carefully applied, models based on factor ceilings are robust tools that can be used for most reasonably abundant species. Probability of occurrence models are based simply on presence-absence data and describe distribution patterns irrespective of abundance, but still provide useful generalisations. The generalised linear models were most sensitive to estuary-specific variations in response and were useful for identifying interaction terms and assessing the relative importance of absolute or estuary standardised sediment mud content. Inevitably, not all appropriate covariables may be measured in a sampling programme and missing data can create hidden biases where effects attributed to habitat variables are confounded with effects due to unmeasured variables associated with other processes (Cade et al. 2005). Our analysis highlights that factors operating across scales may compound these problems, but the use of different types of model, incorporation of natural history information, and the testing of hypotheses concerning the relationships between models developed at different scales may help in determining the limits of extrapolation in the application and interpretation of speciesenvironment models.

Although it is generally accepted that detecting relationships is best done with wide ranges of the explanatory factor (Allen \& Hoekstra 1991), fit of both probability of occurrence and maximum density models was frequently best at the $2 \mathrm{~km}$ extent scale, despite the very small range in sediment mud content. However, it is important not to confuse a good model fit with the ability to predict beyond the bounds of the data. Even when model fit at the smallest scale $(2 \mathrm{~km}$ extent from 1 area of an estuary), was high (>90\%), this did not translate into an ability to extrapolate from the small scale to any larger scale. The better model fit at smaller scales thus seems a reflection of lower variability associated with smaller ranges in other variables, both biotic and abiotic, that may affect species responses to mud content.

In the effort to incorporate scale, many studies concentrate on spatial extent and do not consider environmental heterogeneity (Izsak \& Price 2001). Yet Karl et al. (2000) observed that the effect of spatial resolution on models of bird-habitat relationships was dependent on the variability of the study area. Generally, ecologists lack knowledge of how spatial extent, habitat or environmental heterogeneity and sample resolution interact to affect both the relationships observed at different spatial and temporal scales and the validity of translating model predictions across scale. Wu et al. (2000) raise the question 'What scaling laws exist for patterns and processes in landscapes that are heterogeneous in various ways?' The predictive species-environment models developed in our study exhibited no consistent changes with scale that could be used to develop a scaling law. Rather this study, together with work by Karl et al. (2000) and Melles et al. (2003), suggests that it is difficult to determine scaling functions for speciesenvironmental relationships due to interactions between different aspects of scale and heterogeneity.

Our study supports the concept of there being no single optimal scale (Thrush et al. 1997, Wu et al. 2000). The differences observed, in predicted absolute abundance (or occurrence), with scale for many taxa suggests that both the environmental heterogeneity that occurs within an estuary (e.g. hydrodynamic variability, tidal height) and factors that vary between 
estuaries (e.g. recruitment and productivity) do affect species-environment relationships. Therefore, data collected over different scales are likely to provide the most general tests of regression models and help to identify the limits to extrapolation.

For the study of species-environmental relationships, terrestrial ecologists often recommend scalingdown, as multiplicative effects can result in emergent properties at broad-scales that cannot be deduced by combining properties of lower levels (Bartel 2000). However, our analysis has revealed that very flat response curves can be generated from broad-scale data when processes interact across scales, highlighting the need to consider estuary specific models. Scaling-down approaches can result in application of models to local situations for which they were not designed (Wright 1997). Similarly, our scale-dependent analysis highlights aspects of distribution or abundance where estuary-specific models would be more informative than broad-based models for some species. However, while we should continue to develop techniques to build better species-environment models and to recognise their limitations in predicting ecological patterns, it is important to acknowledge that even simple models may fit certain purposes of resource management. For example, the general pattern of which species prefer muddy or sandy habitats or which species prefer an intermediate sediment type are sufficiently consistent, across scales, that a rank order classification of species can be developed. Such a classification could be incorporated with other predictions of habitat change in environmental risk assessments or be used to interpret changes in the distribution and abundance of monitored species.

\section{CONCLUSION}

Our results emphasise that there is no right scale from which to construct species-environment models, and suggest that, in order to derive general predictive models, consideration needs to be given to both environmental heterogeneity and spatial extent. Spatial extent then serves as a surrogate for variations in broad-scale factors affecting a species ecology. Moreover, important information can be derived from examining differences between models at different scales, particularly when broad-scale models show flat response curves indicative of low sensitivity to the environmental factor of interest. In such cases broad-scale models may be subsuming important factors that mediate direct relationships. Utilizing different types of model to describe species-environment relationships can be useful in helping to explain different aspects of a species spatial structure at different scales. But most importantly, the assessment of model validity needs to focus on the possibility of scale dependence, species ecology and the effect of mediating factors, rather than determining how well the model predicts over the small-scale variability observed.

Acknowledgements. We thank Alf Norkko, Jo Ellis, Greig Funnell, Vonda Cummings, Sara Hatton, Katrin Berkenbusch, Michael Ahrens and Pip Nicholls for their assistance with fieldwork and sample analysis. This work was funded by FRST (NZ) CO1X0307, and T.Y. was supported by the National Institute for Coastal and Marine Management/RIKZ (The Netherlands) under project RKS-889. This is contribution no. 3730 of the Netherlands Institute of Ecology (NIOO-KNAW).

\section{LITERATURE CITED}

Allen TFH, Hoekstra TW (1991) Role of heterogeneity in scaling of ecological systems under analysis. In: Kolasa J, Pickett STA (eds) Ecological heterogeneity. SpringerVerlag, New York, p 47-68

Bartel A (2000) Analysis of landscape pattern: towards a 'top down' indicator for evaluation of landuse. Ecol Model 130: 87-94

Blackburn TM, Lawton JH, Perry JN (1992) A method of estimating the slope of upper bounds of plots of body size and abundance in natural animal assemblages. Oikos 65: 107-112

Burnham KP, Anderson DR (1998) Model selection and multimodel inference. Springer, New York

Cade BS, Noon BR, Flather CH (2005) Quantile regression reveals hidden bias and uncertainty in habitat models. Ecology 86:786-800

Cummings VJ, Thrush SF, Hewitt JE, Funnell GA (2001) Variable effect of a large suspension-feeding bivalve on infauna: experimenting in a complex system. Mar Ecol Prog Ser 209:159-175

Cushman SA, McGarigal K (2002) Hierarchical, multi-scale decomposition of species-environment relationships. Landscape Ecol 17:637-646

Ellis JI, Schneider DC (1997) Evaluation of a gradient sampling design for environmental impact assessment. Environ Monit Assess 48:157-172

Grand J, Cushman SA (2003) A multi-scale analysis of species-environment relationships: breeding birds in a pitch pine-scrub oak (Pinus rigida-Quercus ilicifolia) community. Biol Conserv 112:307-317

Gray JS (1974) Animal-sediment relationships. Oceanogr Mar Biol Annu Rev 12:707-722

Herman PMJ, Middelburg JJ, VandeKoppel J, Heip CHR (1999) Ecology of estuarine macrobenthos. Adv Ecol Res 29:195-231

Hurvich CM, Tsai C L (1989) Regression and time series model selection in small samples. Biometrika 76:297-307

Izsak C, Price ARG (2001) Measuring beta-diversity using a taxonomic similarity index, and its relation to spatial scale. Mar Ecol Prog Ser 215:69-77

Karl JW, Heglund PJ, Garton EO, Scott JM, Wright NM, Hutto RL (2000) Sensitivity of species habitat-relationship model performance to factors of scale. Ecol Appl 10:1690-1705

Levinton J, Kelaher B (2004) Opposing organizing forces of deposit-feeding marine communities. J Exp Mar Biol Ecol 300:65-82

Lohrer AM, Thrush SF, Hewitt JE, Berkenbusch K, Ahrens 
MA, Cummings VJ (2004) Terrestrially derived sediment: response of marine macrobenthic communities to thin terrigenous deposits. Mar Ecol Prog Ser 273:121-138

Melles S, Glenn S, Martin K (2003) Urban bird diversity and landscape complexity: species-environment associations along a multi-scale habitat gradient. Conserv Ecol 7:5. Available at www.consecol.org/vol7/iss1/art5

Norkko A, Hewitt JE, Thrush SF, Funnell GA (2001) Benthicpelagic coupling and suspension feeding bivalves: linking site-specific sediment flux and biodeposition to benthic community structure. Limnol Oceanogr 46:2067-2072

Olden JD, Jackson DA (2000) Torturing data for the sake of generality: how valid are our regression models? Ecoscience 7:501-510

O'Neill RV, Gardner RH, Milne BT, Turner MG, Jackson B (1991) Heterogeneity and spatial hierarchies. In: Kolasa J, Pickett STA (eds) Ecological Heterogeneity. SpringerVerlag, New York, p 85-96

Pearson TH, Rosenberg R (1987) Feast and famine: structuring factors in marine benthic communities. In: Gee JHR, Giller PS (eds) Organisation of communities past and present. Blackwell Scientific Publications, Oxford, p 373-395

Sartory DP (1982) Spectrophotometric analysis of chlorophyll $a$ in freshwater phytoplankton. Hydrological Research Institute Technical Report TR 115, Pretoria

Thomson JD, Weiblen G, Thompson BA, Alfaro S, Legendre P (1996) Untangling multiple factors in spatial distributions: lilies, gophers and rocks. Ecology 77:1698-1715

Thrush SF, Schneider DC, Legendre P, Whitlatch RB and 8 others (1997) Scaling-up from experiments to complex ecological systems: Where to next? J Exp Mar Biol Ecol 216:243-254

Editorial responsibility: John Gray (Contributing Editor), Oslo, Norway
Thrush SF, Hewitt JE, Norkko A, Nicholls PE, Funnell GA, Ellis JI (2003) Habitat change in estuaries: predicting broad-scale responses of intertidal macrofauna to sediment mud content. Mar Ecol Prog Ser 263:113-125

Van Belle G (2002) Statistical rules of thumb. Wiley Interscience, New York

Warwick RM, Goss-Custard JD, Kirby R, George CL, Pope ND, Rowden AA (1991) Static and dynamic environmental factors determining the community structure of estuarine macrobenthos in SW Britain: why is the Severn Estuary different? J Appl Ecol 28:329-345

Wiens JA (1989) Spatial scaling in ecology. Funct Ecol 3: 385-397

Wright N (1997) Wildlife habitat relationship models for terrestrial vertebrate species on Craig Mountain, Idaho. Idaho Cooperative Fish and Wildlife Research Unit, University of Idaho, Moscow, ID

Wu J, Loucks OL (1995) From balance of nature to hierarchical patch dynamics: a paradigm shift in ecology. Q Rev Biol 70:439-466

Wu JC, Jelinski DE, Luck M, Tueller PT (2000) Multiscale analysis of landscape heterogeneity: scale variance and pattern metrics. Geogr Inform Sci 6:6-19

Ysebaert T, Herman PMJ (2002) Spatial and temporal variation in benthic macrofauna and relationships with environmental variables in an estuarine, intertidal soft-sediment environment. Mar Ecol Prog Ser 244: 105-124

Ysebaert T, Meire P, Herman PMJ, Verbeek H (2002) Macrobenthic species response surfaces along estuarine gradients: prediction by logistic regression. Mar Ecol Prog Ser 225:79-95

Submitted: June 10, 2004; Accepted: May 17, 2005

Proofs received from author(s): October 13, 2005 